\title{
Association between physical performance and muscle strength among
}

\author{
elderly \\ Basma G.Azab ${ }^{1}$, Heba Y. Youssif', Manar MA. Maamoun ${ }^{1}$.Hala S. Sweed ${ }^{1}$ \\ ${ }^{1}$ Geriatrics and Gerontology department, Faculty of Medicine, Ain Shams University, Cairo, \\ Egypt
}

\begin{abstract}
Aim: Studies about the relationships between muscle mass, muscle strength and physical performance in Egyptian elderly are scarce.The current study aimed to investigate the relationships between muscle mass, muscle strength and physical performance in a sample of older Egyptians. Methods: The study was a case-control study conducted on 76 elderly subjects, aged from 60 -75 years old,males and females,recruited from geriatric outpatient clinic, Ain Shams University hospital. Subjects were divided according to gait speed ( measured by four meters walking test)as indicator of physical performance into two groups,cases:38 subjects withlow gait speed $(<0.8 \mathrm{~m} / \mathrm{s})$, and controls: 38 subjects with normal gait speed $(\geq 0.8$ $\mathrm{m} / \mathrm{s}$ ). Appendicular skeletal mass (ASM) was measured by dual-energy X-ray absorptiometry and skeletal muscle index (SMI) was calculated, whereas, grip strength was measured by dynamometer(Jamar Hydraulic hand dynamometer)for all participants Results: Muscle mass was not significantly different between the two groups whereas, Muscle strength was significantly lower in subjects with impaired physical performance measured by gait $\operatorname{speed}(89 \%, \mathrm{p}=<0.01)$.There was a significant inverse correlations between muscle strength, height and the gait speed in seconds $(\mathrm{p}=<0.01, \mathrm{p}=<0.05)$ respectively. Low muscle strength and advanced age were significant independent predictors of low gait speed among studied population. Conclusion: Muscle strength has greater effect on physical performance than muscle mass among elderly subjects. Programs that target muscle strength can have great impact on the physical function and quality of life of the elderly.
\end{abstract}

Keywords: Muscle strength, muscle mass, Elderly, Physical performance

\section{Introduction}

One of the main characteristics of aging process is loss of muscle mass, muscle strength and subsequent functional decline. The relationships between the three parameters in elderly were a major research question in the last decades all over the world. The European Working Group on Sarcopenia in Older People (EWGSOP) recommends muscle mass, muscle strength and physical performance as primary outcome variables for intervention trials of sarcopenia $^{(1)}$. Several studies strongly suggested that the loss of muscle strength with aging was largely independent of the loss of muscle mass ${ }^{(2)}$ Kim and his colleagues found that muscle mass decline explained only $5 \%$ of the decline in strength and the rate of strength decline was about three times greater than the rate of lean mass loss ${ }^{(3)}$ Low muscle strength is predictive of functional limitation and physical disability in older people ${ }^{(4)}$.With increasing age, there was a 10-18\% successive decline in performance throughout the entire age $\operatorname{span}^{(5)}$.

Grip strength is a good simple measure of muscle strength. Isometric hand grip strength is strongly related with lower extremity muscle power and low handgrip strength is a clinical marker of poor mobility and a better predictor of clinical outcomes than low muscle mass ${ }^{(6)}$, in practice, there was also a 
linear relationship between baseline handgrip strength and incident disability for activities of daily living (ADL) ${ }^{(7)}$

Several studies strongly suggested that the loss of muscle strength with aging was largely independent of the loss of muscle mass and muscle weakness carried a greater relative risk for the development of disability than low muscle mass. The number and magnitude of associations for low physical performance or disability were found to be greater for low muscle strength than low muscle mass ${ }^{(4)}$.

Scarce data are available regarding Egyptian elderly,Hence the aim of the current study is to assess the relationship between muscle strength, muscle mass and physical performance among community dwelling elderly subjects.

\section{Subjects and Methods}

Design: A case control study was conducted on 76 elderly participants (34 males and 42 females) aged 60-75 years,independent in activities of daily living (ADL)\& instrumental activities of daily living(IADL), randomly selected fromgeriatric outpatient clinic,Ain Shams University Hospital.Subjectswith cognitive impairment as measured by mini-mental status examination, liver cell failure, respiratory failure, heart failure and renal failure, hemoglobin less than 10 gldl,peripheral neuropathy, past or current history of malignancy,severe knee osteoarthritis, any history of inflammatory joint diseases, neurological disorder or injury to upper extremityand lower extremities that may affect the tests performance were excluded from the study.

Methods:After taking informed consent, each participant subjected to full history taking (demographic data, medical history, review of medications),clinical examination. Assessment of physical performance by fourmeters walking test,a cut-off point of $<0.8$ $\mathrm{m} / \mathrm{s}$ identifies subjects with poor physical performance ${ }^{(6)}$.Measurement of hand grip strength of dominant hand using a dynamometer (Jamar Hydraulic hand dynamometer; 5030J1Sammons Preston USA). low muscle strength was classified as hand grip strength less than $30 \mathrm{~kg}$ and $20 \mathrm{~kg}$ in men and women, respectively ${ }^{(6)}$ ${ }^{(8)}$ Estimation of appendicular Muscle mass was estimated by a dual energy X-ray absorptiometry (DXA) (total -body) (GE Lunar Radiation Corporation, 726 Heartland Trail, Madison, WI 53717-1915).The lean mass of the four limbs was summed from a DXA scan as appendicular skeletal muscle mass (ASM) divided by height squared and defined a skeletal muscle mass index: (SMI) as ASM/height2 $(\mathrm{kg} / \mathrm{m} 2) \mid$ Cut off point of normal muscle mass measured by a DXA scan is (SMI) $7.26 \mathrm{~kg} / \mathrm{m} 2,5.5 \mathrm{~kg} / \mathrm{m} 2$ in men and women, respectively ${ }^{(9)}$.

Ethical considerations: Informed consent was taken from every elder participating in this study. The study methodology was reviewed and approved by the ethical committee, Faculty of Medicine, Ain Shams University

Statistical analysis: Data was processed and analyzed using SPSS (Statistical Package for Social Science) software version 20.0.The data was presented using frequency \& its related percentage. Comparison between groups was done using chi-square test; Fisher Exact test was used when the expected count in more than or equal $25 \%$ of the cells was less than 5.The risk factors for poor physical performance were analyzed by both univariate and Logestic regression methods.Independent sample t-test was used to compare between means of two independent groups. A P value of 0.05 was chosen as a level of significance. $\mathrm{P}>0.05$ is insignificant, $\mathrm{P}<0.05$ is significant and $\mathrm{p}<0.01$ is highly significant.

\section{Results}

The current study revealed that more than half of studiedpopulation (53.9\%) had low muscle strength while only $18.4 \%$ had low 
muscle mass, and sarcopenia were diagnosed in $11.8 \%$ of total population. After subdivision of subjects according to gait speed as indicator of physical performance. Cases with poor physical performance were significantly shorter, thinner and had more comorbidities than control group (table 1). Cases had significantly lower muscle strength ( $89.5 \%$ vs $18.4 \%$ ) and sarcopenia $(21.1 \%$ vs $2.6 \%)$ than controls $(\mathrm{p}=<0.01)$ $(\mathrm{p}=<0.05)$ respectively. While low muscle mass represents $(21.1 \%)$ in cases and $(15.8 \%)$ in controls with no significant difference between two groups. (table2).

Factors inversely correlated with gait speed in seconds were muscle strength and height $(\mathrm{p}<0.00, \mathrm{p}<0.05$ respectively) while muscle mass, weight,BMI and age had nonsignificant correlations (table3).Muscle strength $(\mathrm{p}=<0.01)$ and age $(\mathrm{p}=<0.05)$ were significant independent predictors of gait speed using logistic regression model. (table4).

\section{Discussion}

A relationship between muscle strength and physical performance may be of importance in identifying individuals who would benefit from early intervention to prevent loss of muscle strength with age ${ }^{(10)}$ the current study showed that low muscle strength is more prevalent than low muscle mass in either total population or subgroups, several studies support the same findings thatthe loss of muscle strength with age is much more rapid than the parallel loss of muscle mass denoting that muscle strength decreased with aging before muscle mass ${ }^{(11)(12)(13)(4)}$

While, the current study failed to find significant difference in prevalence of low muscle mass between two groups, sarcopenia is significantly more prevalent in caseswhich demonstrate the key role of low muscle strength in sarcopenia and support the use the term "dynapenia" instead of sarcopenia to describe the age related loss of muscle strength regardless muscle mass as recommended by The European Working
Group on Sarcopenia in Older People (EWGSOP) $^{(1)}$

In agreement with several studies the current study showed that cases are shorter, thinner and have more comorbidities than control $\operatorname{group}^{(14)(15)(4)(16)}$.

Studies concerning the relation between muscle strength and physical performance showed variable results with a general agreement that muscle strength is an independent predictor of physical performance regardless the tools used for measurement. While the role of muscle mass showed diverse results and much debate exist about its association with physical performance.

Several studies agreed with the current study that muscle strength, not muscle mass, was a significant independent predictor of gait speed in older people and muscle strength is associated with poor physical performance as demonstrated by the significant inverse correlation between muscle strength and gait speed in seconds (17)(18)(19) (20)(21)(22)(23) (24) (4) (25) (26) (10).

Samuel and colleagues measured muscle strength at the knee and hip joints using a torque dynamometer, Functional assessment was done by three-dimensional biomechanical analysis of gait, chair rise and sit-down, stair ascent and descent and body mass was assessed by anthropometric measures. Theyfound that loss of muscle strength was independently associated with poorer functional ability ${ }^{(10)}$.

Hicks et al (2011) found, in a longitudinal analysis of 934 adults aged $\geq 65$ years followed after 3 and 6 years that low muscle strength was particularly powerful risk factor of functional limitation in elderly subjects. Muscle strength was measured by knee extension strength,grip strength, muscle mass by DXA and Mobility function using gait speed and self-reported mobility disability.

Hairi et al., (2010) confirmed the same results, in a large study enrolled one thousand seven hundred five community-dwelling men aged 70 and above that muscle strength was 
the single best measure of age-related muscle change and low muscle strength was associated with physical disability in IADLs and functional limitation.

Supporting our results in a cross-sectional study of 542 older men and women aged (65-97 years) using the baseline data from the Korean Longitudinal Study on Health and Aging. Short Physical Performance Battery (SPPB) was used to assess physical performance and the appendicular skeletal muscle mass (ASM) (kg) was measured using DXA,there was no association between muscle mass and physical performance ${ }^{(3)}$.

Also, Visserand colleagues found that there was no association between total body muscle mass or leg muscle mass and selfreported disability for either men or women. They measured skeletal muscle mass by dualenergy X-ray absorptiometry (DXA) ${ }^{(27)}$.

In contrast with the current study, a cross sectional studyof Fifty-seven older males and females aged (67- 81 years) demonstrated that muscle mass was an important determinant of physical performance among functionally-limited elders. Functional performance was assessed by Short Physical Performance Battery test (SPPB) muscle mass was measured using DXA, and muscle strength was estimated at the hip joint using pneumatic double leg press resistance machine ${ }^{(28)}$.

Janssen et al., (2002) also found in a large study enrolled four thousand five hundred four adults aged 60 and above using data from the Third National Health and Nutrition Examination Survey (NHANES III) that low skeletal muscle mass was significantly and independently associated with functional impairment and disability, Skeletal muscle mass was measured using bioimpedance analysis measurements and functional limitations, was defined as difficulty in performing at least three of five functional living tasks ${ }^{(29)}$.

The discrepancy in results concerning the relation between musclemass and physical performance, signifies the role of considering muscle quality as a determinable factor in delineating the relation between muscle mass and physical function.

\section{Conclusion}

Low muscle strength is associated with impaired physical performance in elderly subjects . Muscle strength and age is a significant independent predictor of gait speed among elderly. there is a significant inverse relation between gait speed in seconds and muscle strength and height.

Acknowledgement: This research was supported by Ain Shams University.

Disclosure statement: No potential conflicts of interest were disclosed.

\section{References:}

1. Cruz-Jentoft AJ, Baeyens JP, Bauer JM, et al. (2010): Sarcopenia. European consensus on definition and diagnosis Report of the European Working Group on Sarcopenia in Older People. Age and Ageing: 39 (4):412-423.

2. Clark BC and Manini TM (2010): Functional consequences of sarcopenia and dynapenia in the elderly. CurrOpinClinNutrMetab Care.;13:271-276.

3. Kim K, Jang S, Lim S et al., (2012): Relationship between muscle mass and physical performance: is it the same in older adults with weak muscle strength? Age and Ageing; 41 (6): 799-803. 
4. Hairi NN, Cumming RG, Naganathan V et al.,(2010): Loss of Muscle Strength, Mass (Sarcopenia), and Quality (Specific Force) and Its Relationship with Functional Limitation and Physical Disability: The Concord Health and Ageing in Men Project.J Am GeriatrSoc. 58(11):2055-2062.

5. Ribom EL, Mellstrom D, Ljunggren $O$ et 1., (2011): Population-based reference values of handgrip strength and functional tests of muscle strength and balance in men aged 7080 years..ArchGerontolGeriatr; 53(2):e114-117.

6. Laurentani F, Russo C, Bandinelli S et al.,(2003): Age-associatedchanges in skeletal muscles and their effect on mobility: anoperational diagnosis of sarcopenia. J ApplPhysiol; 95:1851-1860.

7. Markides $\mathrm{K}, \mathrm{Al}$ Snih S, Ottenbacher $\mathrm{K}$, et al. (2004): Hand grip strength and incident ADL disability in elderly Mexican Americans over a seven-year period. Aging ClinExp Res.; 16: 481-486.

8. Roberts HC,Denison HJ, Martin HJ et al., (2011): A review of the measurement of grip strength in clinical and epidemiological studies: towards a standardized approach. Age and Ageing ; 40(4):423-429.

9. Baumgartner R, Koehler K, Gallagher D et al., (1998): Epidemiology of sarcopenia among the elderly in New Mexico. Am J Epidemiol; 147: 755-763.

10. Samuel D, Rowe P, Hood V et al., (2012): The relationships between muscle strength, biomechanical functional moments and healthrelated quality of life in non-elite older adults. Age and Ageing; 41 (2): 224-230.
11. Evans W (1995): What is sarcopenia? J Gerontol A BiolSci Med Sci;50A:5-8.

12. Doherty TJ (2003): Aging and sarcopenia. J ApplPhysiol; 95:17171727.

13. Rolland Y, Czerwinski S, Abellan Van Kan G et al.,(2008):Sarcopenia:its assessment, etiology, pathogenesis, consequences and future perspectives. J Nutr Health Aging; 12: 433-450.

14. Roberts HC, Denison HJ, O'Donnell DEet al., (2007): Patterns of cardiopulmonary response to exercise in lung diseases. European Respiratory Monograph;.69-92.

15. Brunner E, Shipley M, Spencer V et al.,(2009): Social Inequality in Walking Speed in Early Old Age in the Whitehall II Study. J Gerontol A BiolSci Med Sci.;64A(10):10821089.

16. Vogiatzis I, Zakynthinos G, and Andrianopoulos V (2012): Mechanisms of Physical Activity Limitation in Chronic Lung Diseases. Pulmonary Medicine; 11:80-91.

17. Hirsch 1 H, Fried I.P, Harris T et al., (1993): Correlates of performancebased measures of muscle function in the elderly: The Cardiovascular Health Study. Gerontol Sled Sci 1447:52A:M142-200

18. Berkman LF, Seeman TF., Albert NI et al., (1993): High, usual and impaired functioning in communitydwelling older men and women: Findings from the MacArthur Foundation Research Network on Successful Aging. J ClinEpidemiol; 46:1129-1140. 
19. Fried LP, Ettinger WH. Lind B et al.,(1994): Physical disability in older adults: a phc:iological approach. ChnEpidemiol 1994;47:747-760.

20. Aviund K, Schroll M, Davidsen M et al., (1994): Maximal isometric muscle strength and functional ability in daily activities among 75year-old men and women. Scand I Sled Sci Sports; 4:32-40.

21. Giampaoli S, Ferrucci L, Cecchi F et al.,(1999): Hand-grip strength predicts incident disability in nondisabled older men. Age Ageing;28:283-288

22. Rantanen T, Guralnik JM, Foley D et al., (1999): Midlife hand grip strength as a predictor of old age disability. JAMA; 281:558-560.

23. Visser $M$, Deeg DJH, Lips $P$ et al.,(2000): Skeletal Muscle Mass and Muscle Strength in Relation to Lower-Extremity Performance in Older Men and Women. j Am GeriatrSoc ;48:381-386.

24. Rantanen T, Guralnik JM, Ferrucci L et al., (2001):Co impairments as predictors of severe walking disability in older women. $\mathrm{J}$ Am GeriatrSoc; 49:21-27.

25. Turner RG, Pignataro RM., DongL et al., (2011): Handgrip strength among older American Indians: the Native Elder Care Study.Age Ageing. July; 40(4): 523-527

26. Hicks GE, Shardell M, Alley D et al., (2011): Absolute Strength and Loss of Strength as Predictors of Mobility Decline in Older Adults: The InCHIANTI Study.J Gerontol A BiolSci Med Sci; 60:221-330.
27. Visser NI, Harris TB, Langlois I et al (1998): Body tat and skeletal muscle mass in Relation to physical disability in very old men and women of the FraminghamHeart Study. J Gerontol Sled Sci;53A:N1214-221.

28. Reid KF, Naumova EN, Carabello R J et al., (2008): Lower extremity muscle mass predicts functional performance in mobility-limited elders. J Nutr Health Aging;12:493498.

29. Janssen I ,Heymsfield SB and Ross R (2002): Low Relative Skeletal Muscle Mass (Sarcopenia) in Older Persons Is Associated with Functional Impairment and Physical Disability. Journal of the American Geriatrics Society;50: 889-896. 


\section{Tables and Graphs}

Table 1: Comparison between the two groups as regard subjects' characteristics

\begin{tabular}{|l|l|l|l|l||}
\hline \multirow{2}{*}{ Patient Characteristics } & $\begin{array}{l}\text { Case } \\
(\mathrm{n}=38)\end{array}$ & $\begin{array}{l}\text { Control } \\
(\mathrm{n}=38)\end{array}$ & $\begin{array}{l}\text { Independent sample t- } \\
\text { test }\end{array}$ & P-value \\
\cline { 2 - 5 } & Mean $\pm \mathrm{SD}$ & Mean $\pm \mathrm{SD}$ & & 0.93 \\
\hline \hline Age (yrs.) & $66.4 \pm 5.2$ & $66.3 \pm 5.3$ & 0.08 & $0.04^{*}$ \\
\hline Weight $(\mathrm{kg})$ & $72.4 \pm 13.3$ & $79.7 \pm 17.1$ & 2.08 & $0.01^{*}$ \\
\hline Height(cm) & $155.4 \pm 9.1$ & $160.6 \pm 8.8$ & 2.49 & 0.54 \\
\hline BMI & $30.1 \pm 6.0$ & $30.9 \pm 6.3$ & 0.61 & 0.80 \\
\hline $\begin{array}{l}\text { Number of medications } \\
\text { used }\end{array}$ & $3.1 \pm 2.3$ & $2.9 \pm 2.1$ & 0.25 & $0.04 *$ \\
\hline Number of co-morbidities & $3.2 \pm 2.0$ & $2.3 \pm 1.4$ & 2.06 & \\
\hline
\end{tabular}

(*) Statistically significant $\mathrm{p}<0.05$

Table 2: Comparison between the two groups as regard Muscle mass, Muscle strength and Presence of sarcopenia

\begin{tabular}{|l|l|l|l|l|}
\hline Variables & $\begin{array}{l}\text { Case } \\
(\mathrm{n}=38)\end{array}$ & $\begin{array}{l}\text { Control } \\
(\mathrm{n}=38)\end{array}$ & $\chi 2$ test & P-value \\
\cline { 2 - 6 } & No.(\%) & No.(\%) & & \\
\hline \hline Low Muscle Mass & $8(21.1)$ & $6(15.8)$ & 0.350 & 0.55 \\
\hline \hline Low Muscle Strength & $34(89.5)$ & $7(18.4)$ & 38.609 & $0.00 * *$ \\
\hline \hline Sarcopenia & $8(21) 1$. & $1(2.6)$ & $6.176 \#$ & 0.01 \\
\hline
\end{tabular}

Low muscle mass $<7.26 \mathrm{~kg} / \mathrm{m} 2$ men low muscle strength $<30 \mathrm{~kg}$ men

$<5.5 \mathrm{~kg} / \mathrm{m} 2$ women $<20 \mathrm{~kg}$ women

(*) Statistically significant $\mathrm{p}<0.05(* *)$ Highly statistically significant $\mathrm{p}<0.01$ (\#) Fisher exact test 
Table 3: Correlation matrix displaying relationship between gait speed in seconds, Muscle strength, Muscle mass, Age, Weight, Height and BMI in the studied population.

\begin{tabular}{|l|l|l||}
\hline Gait Speed & $\mathrm{R}$ & Sig. (2-tailed) \\
\hline Muscle strength & $-0.530^{* *}$ & $0.00^{* *}$ \\
\hline Muscle mass & -0.177 & 0.22 \\
\hline Age & 0.035 & 0.81 \\
\hline Weight & -0.026 & 0.85 \\
\hline Height & $-0.291^{*}$ & $0.04^{*}$ \\
\hline BMI & 0.110 & 0.45 \\
\hline
\end{tabular}

**. Correlation is significant at the 0.01 level (2-tailed).*. Correlation is significant at the 0.05 level (2-tailed).

Table 4: Logistic Regression Model Revealing Variables independently associated with Gait Speed in the studied population

\begin{tabular}{|l|l|l|l||}
\hline Variables & Sig. & Odd ratio & $95 \%$ C.I \\
\hline \hline Age & $0.04^{*}$ & 0.83 & $0.69-0.98$ \\
\hline Weight & 0.36 & 0.95 & $0.87-1.05$ \\
\hline Height & 0.66 & 0.88 & $0.52-1.505$ \\
\hline Education & 0.69 & 1.38 & $0.27-6.87$ \\
\hline Number of Comorbidities & 0.74 & 0.91 & $0.53-1.56$ \\
\hline Knee arthritis & 0.13 & 4.13 & $0.63-26.78$ \\
\hline Cervical spondylosis & 0.48 & 2.93 & $0.14-61.46$ \\
\hline Muscle strength & $0.00^{* *}$ & 47.74 & $7.18-31.74$ \\
\hline Sarcopenia & 0.36 & 3.47 & $0.23-52.27$ \\
\hline
\end{tabular}

(*) Statistically significant at $\mathrm{p}<0.05(* *)$ Highly statistically significant at $\mathrm{p}<0.01$ 